\title{
Sliding Mode Power Control of Variable-Speed Wind Energy Conversion Systems
}

\author{
Brice Beltran, Tarek Ahmed-Ali, and Mohamed El Hachemi Benbouzid, Senior Member, IEEE
}

\begin{abstract}
This paper addresses the problem of controlling power generation in variable-speed wind energy conversion systems (VS-WECS). These systems have two operation regions depending on the wind turbine tip-speed ratio. They are distinguished by minimum phase behavior in one of these regions and a nonminimum phase in the other one. A sliding mode control strategy is then proposed to ensure stability in both operation regions and to impose the ideal feedback control solution despite model uncertainties. The proposed sliding mode control strategy presents attractive features such as robustness to parametric uncertainties of the turbine and the generator as well as to electric grid disturbances. The proposed sliding mode control approach has been simulated on a 1.5-MW three-blade wind turbine to evaluate its consistency and performance. The next step was the validation using the National Renewable Energy Laboratory (NREL) wind turbine simulator called the fatigue, aerodynamics, structures, and turbulence code (FAST). Both simulation and validation results show that the proposed control strategy is effective in terms of power regulation. Moreover, the sliding mode approach is arranged so as to produce no chattering in the generated torque that could lead to increased mechanical stress because of strong torque variations.
\end{abstract}

Index Terms-Power generation control, sliding mode control, wind energy conversion system.

\begin{tabular}{lll}
\multicolumn{4}{c}{ NOMENCLATURE } \\
$B_{g}$ & $\begin{array}{l}\text { Generator external stiffness (newton meter/radian } \\
\text { second). }\end{array}$ \\
$B_{r}$ & $\begin{array}{l}\text { Rotor external stiffness (newton meter/radian } \\
\text { second). }\end{array}$ \\
$C_{p}(\lambda)$ & $\begin{array}{l}\text { Power coefficient. } \\
C_{q}(\lambda)\end{array}$ & Torque coefficient. \\
$J_{g}$ & Generator inertia (kilogram meter $^{2}$ ). \\
$J_{r}$ & Rotor inertia (kilogram meter ${ }^{2}$ ). \\
$K_{g}$ & Generator external damping (newton meter/radian \\
& second). \\
$K_{r}$ & Rotor external damping (newton meter/radian \\
& second). \\
$n_{g}$ & Gearbox ratio. \\
$P_{a}$ & Aerodynamic power (watt). \\
$P_{g}$ & Generated power (watt). \\
$R$ & Rotor radius (meter).
\end{tabular}

Manuscript received April 16, 2007; revised July 12, 2007. Paper No. TEC00108-2007.

B. Beltran and M. E. H. Benbouzid are with the Laboratoire Brestois de Mécanique et des Systèmes (LBMS), University of Western Brittany, Brest 29238, France (e-mail: brice.beltran@dga.defense.gouv.fr; m.benbouzid@ ieee.org).

T. Ahmed-Ali is with the Laboratoire Brestois de Mécanique et des systèmes (LBMS), Ecole Nationale Supérieure d'Ingénieurs des Etudes et Techniques d'Armement (ENSIETA), Brest 29806, France (e-mail: ahmedata@ ensieta.fr).

Color versions of one or more of the figures in this paper are available online at http://ieeexplore.ieee.org.

Digital Object Identifier 10.1109/TEC.2007.914163

\author{
$T_{a} \quad$ Aerodynamic torque (newton meter). \\ $T_{\text {em }} \quad$ Generator electromagnetic torque (newton meter). \\ $T_{g} \quad$ Generator torque in the rotor side (newton meter). \\ $T_{\mathrm{hs}} \quad$ High-speed torque (newton meter). \\ $T_{\mathrm{ls}} \quad$ Low-speed torque (newton meter). \\ $\lambda \quad$ Tip speed ratio (TSR). \\ $v \quad$ Wind speed (meter/second). \\ $\rho \quad$ Air density (kilogram $/$ meter $^{3}$ ). \\ $\omega_{r} \quad$ Rotor speed (radian/second). \\ $\omega_{r} \quad$ Generator speed (radian/second).
}

\section{INTRODUCTION}

W IND ENERGY conversion is the fastest-growing energy source among the new power generation sources in the world and this tendency should remain for some time. Already now, wind energy is rapidly developing into a mainstream power source in many countries of the world, with over $60000 \mathrm{MW}$ of installed capacity worldwide. Under an advanced wind energy growth projection, coupled with ambitious energy saving, wind power could be supplying $29.1 \%$ of the world electricity by 2030 and $34.2 \%$ by 2050 (Fig. 1) [1].

Harnessing wind energy for electric power generation is an area of research interest and nowadays the emphasis is on the cost-effective utilization of this energy aiming at quality and reliability in the electricity delivery [2], [3]. During the last two decades, wind turbine sizes have been developed from $20 \mathrm{~kW}$ to $2 \mathrm{MW}$, while even larger wind turbines are being designed. Moreover, a lot of different concepts have been developed and tested [4].

Currently, variable-speed wind energy conversion systems (VS-WECS) are continuously increasing their market share, since it is possible to track the changes in wind speed by adapting shaft speed, and thus, maintaining optimal power generation. The more VS-WECS are investigated, the more it becomes obvious that their behavior is significantly affected by the control strategy used. Typically, the VS-WECS use aerodynamic controls in combination with power electronics to regulate torque, speed, and power. The aerodynamic control systems, usually variable-pitch blades or trailing-edge devices, are expensive and complex, especially when the turbines are larger. This situation provides an incentive to consider alternative control approaches.

The prime control objective of the VS-WECS is not only power efficiency maximization but also improved dynamic characteristics, resulting in the reduction of the drive train mechanical stresses and output power fluctuations [5]. To achieve power efficiency maximization, the turbine tip-speed ratio should be maintained at its optimum value despite wind variations. Nevertheless, control is not always aimed at capturing as much energy 


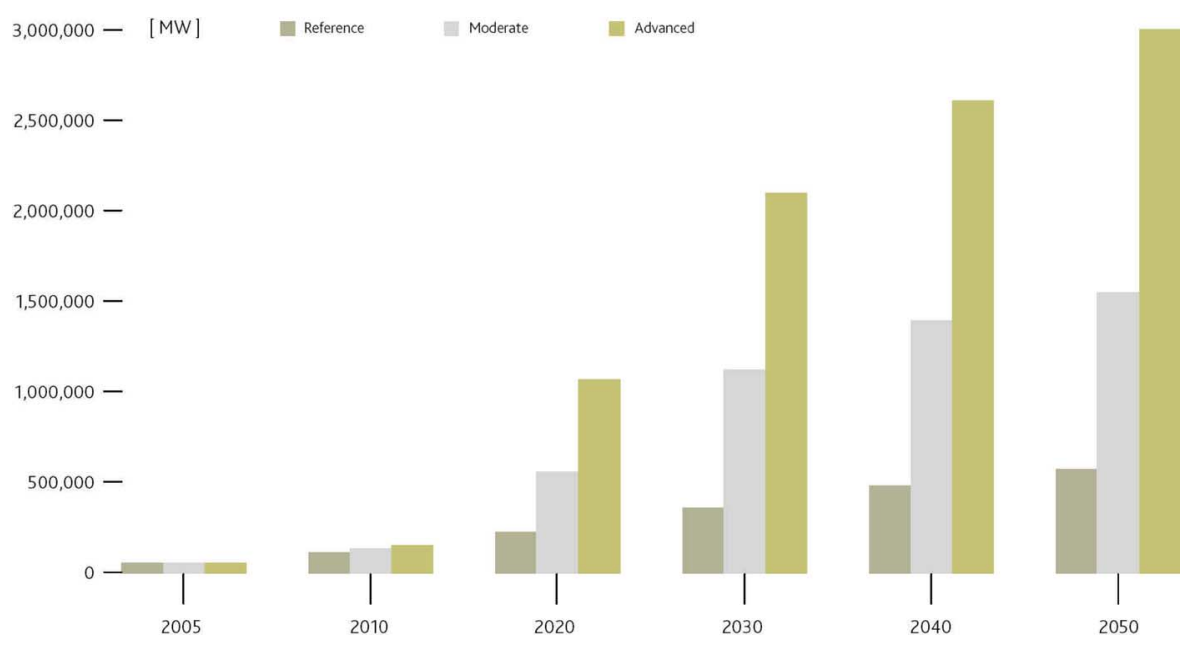

Fig. 1. Global cumulative wind power capacity [1].

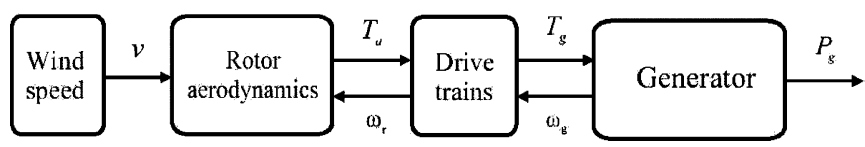

Fig. 2. VS-WECS global scheme.

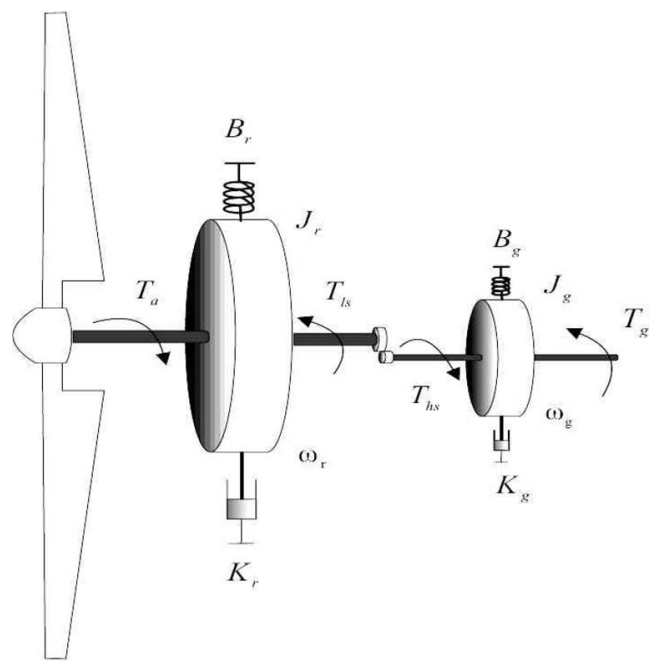

Fig. 3. WECS drive train dynamics.

as possible. In fact, in above-rated wind speed, the captured power needs to be limited. Although there are both mechanical and electrical constraints, the more severe ones are commonly on the generator and the converter. Hence, regulation of the power produced by the generator (i.e., the output power) is usually the prime objective and this is the main objective of this paper.

\section{WIND TURBINE MODELING}

The global scheme for the VS-WECS is given by Fig. 2. The system modeling is inspired from [6] and [7]. Moreover, a fixedpitch variable-speed wind turbine, which is considered in this paper, could be schematically represented by Fig. 3 .
The aerodynamic power $P_{a}$ captured by the wind turbine is given by

$$
P_{a}=\frac{1}{2} \pi \rho R^{2} C_{p}(\lambda) v^{3}
$$

where $C_{p}$ represents the wind turbine power conversion efficiency. It is a function of the tip-speed ratio $\lambda$, as well as the blade pitch angle $\beta$ in a pitch-controlled wind turbine. $\lambda$ is defined as the ratio of the tip speed of the turbine blades to wind speed, and is given by

$$
\lambda=\frac{R \omega_{r}}{v} .
$$

The $C_{p}-\lambda$ characteristics, for different values of the pitch angle $\beta$, are illustrated in Fig. 4. This figure indicates that there is one specific $\lambda$ at which the turbine is most efficient. Normally, a variable-speed wind turbine follows the $C_{p \max }$ to capture the maximum power up to the rated speed by varying the rotor speed to keep the system at $\lambda_{\text {opt }}$. Then, it operates at the rated power with power regulation during high-wind periods by active control of the blade pitch angle or passive regulation based on aerodynamic stall [9].

The rotor power (aerodynamic power) is also defined by

$$
P_{a}=\omega_{r} T_{a} .
$$

Moreover

$$
C_{q}(\lambda)=\frac{C_{p}(\lambda)}{\lambda} .
$$

It, thus, follows that the aerodynamic torque is given by

$$
T_{a}=\frac{1}{2} \pi \rho R^{3} C_{q}(\lambda) v^{2} .
$$

According to Fig. 3, the aerodynamic torque $T_{a}$ will drive the wind turbine at the speed $\omega_{r}$. The low-speed torque $T_{\mathrm{ls}}$ acts as a braking torque on the rotor. The generator is driven by the highspeed torque $T_{\mathrm{hs}}$ and braked by the generator electromagnetic torque $T_{\mathrm{em}}$. Through the gearbox, the rotor speed is increased by the gearbox ratio $n_{g}$ to obtain the generator speed $\omega_{g}$ while the low-speed torque is augmented. 

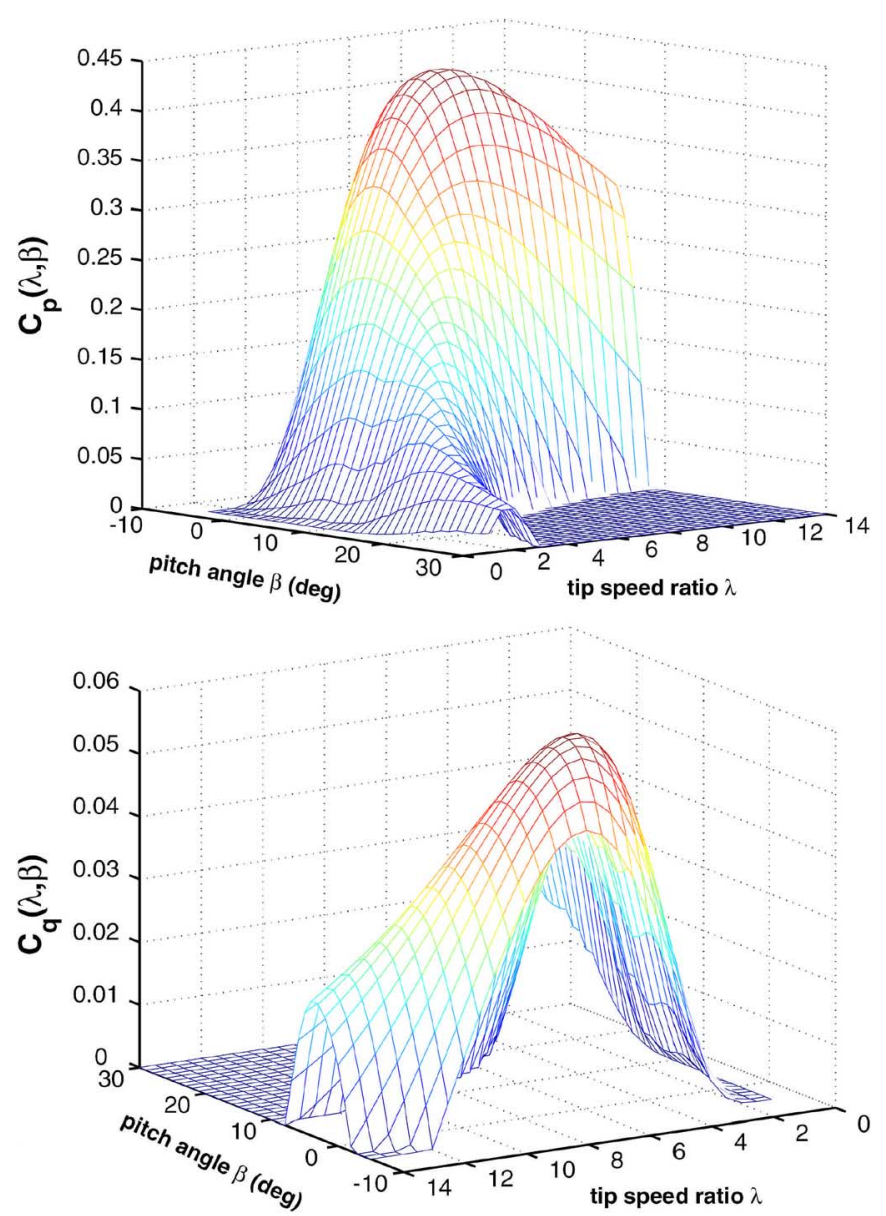

Fig. 4. Wind turbine power and torque coefficients [8].

The rotor dynamics together with the generator inertia are characterized by the following differential equations:

$$
\left\{\begin{array}{l}
J_{r} \dot{\omega}_{r}=T_{a}-K_{r} \omega_{r}-B_{r} \theta_{r}-T_{\mathrm{ls}} \\
J_{g} \dot{\omega}_{g}=T_{\mathrm{hs}}-K_{g} \omega_{g}-B_{g} \theta_{g}-T_{\mathrm{em}}
\end{array} .\right.
$$

The gearbox ratio is defined as

$$
n_{g}=\frac{\omega_{g}}{\omega_{r}}=\frac{T_{\mathrm{ls}}}{T_{\mathrm{hs}}} .
$$

It, thus, follows that

$$
J_{t} \dot{\omega}_{r}=T_{a}-K_{t} \omega_{r}-B_{t} \theta_{r}-T_{g}
$$

where

$$
\left\{\begin{array}{l}
J_{t}=J_{r}+n_{g}^{2} J_{g} \\
K_{t}=K_{r}+n_{g}^{2} K_{g} \\
B_{t}=B_{r}+n_{g}^{2} B_{g} \\
T_{g}=n_{g} T_{\mathrm{em}}
\end{array} .\right.
$$

Since the external stiffness $B_{t}$ is very low, it can be neglected (the combined inertia of the generator and the rotor is dominating). This leads to represent the drive train as a single lumped mass for control purposes [8], [10] (Fig. 5)

$$
J_{t} \dot{\omega}_{r}=T_{a}-K_{t} \omega_{r}-T_{g} .
$$

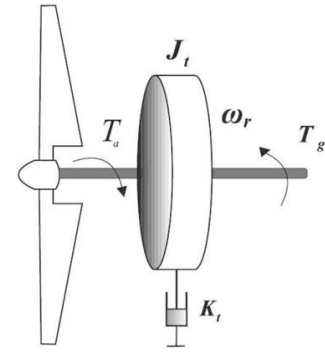

Fig. 5. Single lumped mass mode of the drive train.

The generated power will finally be given by

$$
P_{g}=T_{g} \omega_{r} .
$$

\section{Robust CONTROL DESIGN}

\section{A. Problem Formulation}

Wind turbines are designed to produce electrical energy as cheaply as possible. Therefore, they are generally designed so that they yield maximum output at wind speeds around $15 \mathrm{~m} / \mathrm{s}$. In case of stronger winds, it is necessary to waste part of the excess energy of the wind in order to avoid damaging the wind turbine. All wind turbines are, therefore, designed with some sort of power control. This standard control law keeps the turbine operating at the peak of its $C_{p}$ curve

$$
T_{g}=k \omega^{2}, \quad \text { with } k=\frac{1}{2} \pi \rho R^{3} \frac{C_{p \max }}{\lambda_{\mathrm{opt}}^{3}}
$$

where $\lambda_{\text {opt }}$ is the optimal tip-speed ratio.

There are two significant problems with this standard control. The first is that there is no accurate way to determine $k$, especially since blade aerodynamics can change significantly over time. Second, even when it is assumed that $k$ can be accurately determined via simulation or experiments, wind speed fluctuations force the turbine to operate off the peak of its $C_{p}$ curve much of the time. Indeed, tight tracing the maximum $C_{p}$ would lead to high mechanical stress and transfer aerodynamic fluctuations into the power system. This, however, will result in less energy capture.

The proposed control strategy will, therefore, reduce the negative effects of both the uncertainty regarding $k$ and the change in optimal operating point due to turbulence.

To effectively extract wind power while at the same time maintaining safe operation, the wind turbine should be driven according to the following three fundamental operating regions associated with wind speed, maximum allowable rotor speed, and rated power [11], [12]. The three distinct regions are shown in Fig. 6, where $v_{\max }$ is the wind speed at which the maximum allowable rotor speed is reached, while $v_{\text {cutoff }}$ is the furling wind speed at which the turbine needs to be shut down for protection.

In practice, there are two possible regions of turbine operation, namely the high- and low-speed regions. High-speed operation (III) is frequently bounded by the speed limit of the machine. Conversely, regulation in the low-speed region (II) is usually not restricted by speed constraints. However, the system has nonlinear nonminimum phase dynamics in this region. 


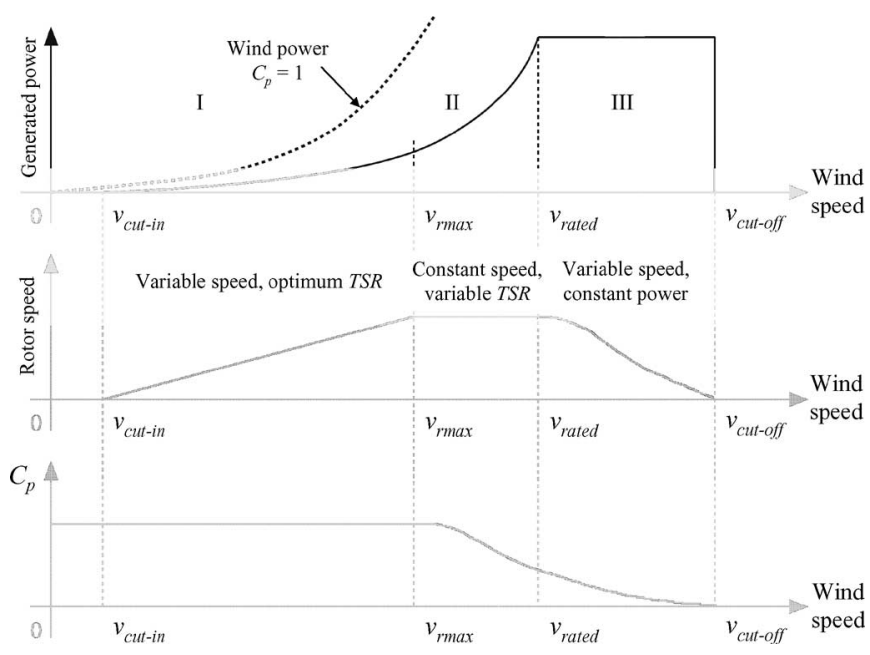

Fig. 6. Optimal efficiency loci depicting the different regions of turbine control.

This adverse behavior is an obstacle to perform the regulation task [11].

A common practice in addressing the control problem of wind turbines is to use a linearization approach. However, due to the stochastic operating conditions and the inevitable uncertainties inherent in the system, such control methods come at the price of poor system performance and low reliability [6]. Hence the need for nonlinear and robust control to take into account these control problems [13].

\section{B. The Proposed Control Strategy}

The proposed generator power control strategy that takes into account the previously discussed problems is as shown in Fig. 7. This strategy is based on a dynamic robust sliding mode controller. Indeed, sliding mode control is one of the effective nonlinear robust control approaches since it provides system dynamics with an invariant property to uncertainties once these are controlled in the sliding mode [14]. Moreover, it is easy to implement. For wind turbine control, sliding mode should provide a suitable compromise between conversion efficiency and torque oscillation smoothing [15]-[19].

As shown, the power reference $P_{\text {ref }}$ is generated by a maximum power point tracking (MPPT) algorithm that searches for the peak power on the power-speed curve [20]-[22].

The adopted dynamic sliding mode scheme uses an adaptive gain that increases as long as the power tracking error is not equal to zero.

Let us consider the tracking error

$$
\varepsilon_{p}=P_{\mathrm{ref}}-P_{g} .
$$

It follows that

$$
\dot{\varepsilon}_{p}=\dot{P}_{\mathrm{ref}}-T_{g} \dot{\omega}_{r}-\dot{T}_{g} \omega_{r}
$$

If we choose the following dynamic sliding mode controller

$$
\dot{T}_{g}=\frac{(B+\lambda) \operatorname{sgn}\left(\varepsilon_{p}\right)}{\omega_{r}}
$$

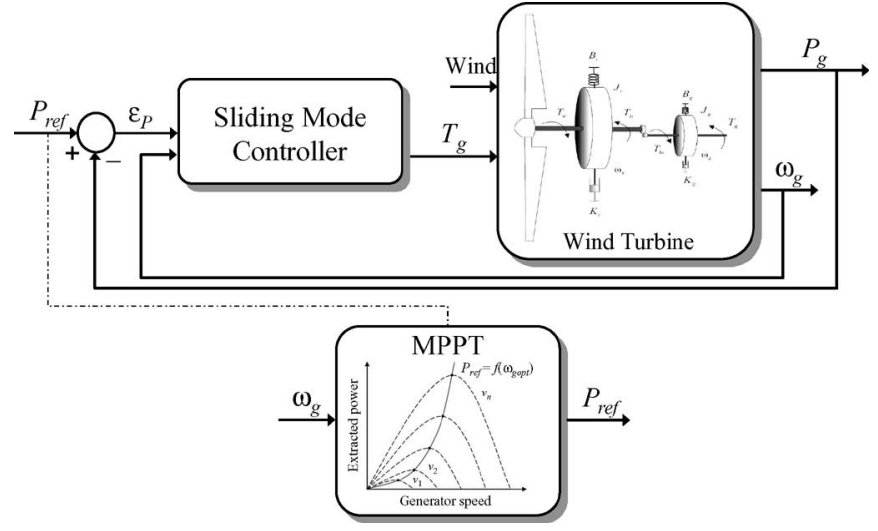

Fig. 7. Proposed control scheme.

with $\dot{B}=\left|\varepsilon_{p}\right|$ and $\lambda>0$, then we obtain

$$
\dot{\varepsilon}_{p}=\dot{P}_{\text {ref }}-T_{g} \dot{\omega}_{r}-(B(t)+\lambda) \operatorname{sgn}\left(\varepsilon_{p}\right) .
$$

Now, if we suppose

$$
d=\dot{P}_{\text {ref }}-T_{g} \dot{\omega}_{r}
$$

as a perturbation that satisfies

$$
|d|<B_{1}
$$

where $B_{1}$ is a positive unknown constant. Then, we can write

$$
\dot{\varepsilon}_{p}=-(B(t)+\lambda) \operatorname{sgn}\left(\varepsilon_{p}\right)+d .
$$

In order to prove the stability of our controller, let us consider the following Lyapunov function.

$$
V=\frac{1}{2} \varepsilon^{2}+\frac{1}{2}\left(B-B_{1}\right)^{2} .
$$

It is not difficult to see that its time derivative well satisfies

$$
\dot{V} \leq-\lambda|\varepsilon| .
$$

From this, and based on the LaSalle theorem, we can conclude that the tracking error converges asymptotically to zero [23].

In order to avoid the chattering phenomena introduced by the function $\operatorname{sgn}($.$) , we will use the following approximation:$

$$
\operatorname{sgn}\left(\varepsilon_{p}\right)=\frac{\varepsilon_{p}}{\left|\varepsilon_{p}\right|+a_{0}}
$$

where $a_{0}$ is a small positive constant. A practical consequence of this approximation is that no chattering will be produced in the generated torque. This will avoid increased mechanical stress due to strong torque variations.

In practice, it is sometime preferable to operate the wind turbine at an efficiency a bit lower than the maximum, with the aim of keeping an energy buffer for grid frequency control to face sudden consumption changes [20], [24]. This issue has, therefore, been adopted in our case leading to

$$
P_{\text {ref }}=0.9 T_{\text {opt }} \omega_{\text {opt }}
$$


TABLE I

WIND TURBINE CHARACTERISTICS

\begin{tabular}{c|c}
\hline \hline Number of blades & 3 \\
\hline Rotor diameter & $70 \mathrm{~m}$ \\
\hline Hub height & $84.3 \mathrm{~m}$ \\
\hline Rated power & $1.5 \mathrm{MW}$ \\
\hline Turbine total inertia & $4.4532 \times 10^{5} \mathrm{~kg} \mathrm{~m}^{2}$ \\
\hline \hline
\end{tabular}

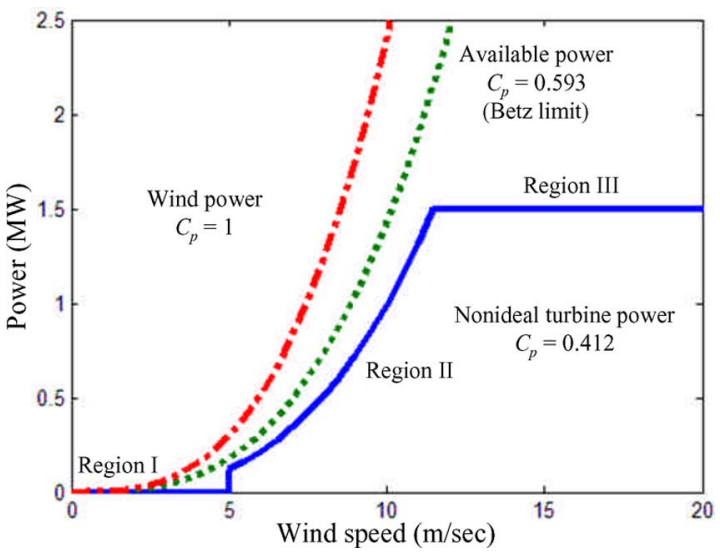

Fig. 8. Steady-state power curves [8].

for weak wind velocities (region II). The generator optimal torque and speed are given by

$$
\left\{\begin{array}{l}
T_{\mathrm{opt}}=\frac{1}{2} \pi \rho R^{3} \frac{C_{p \max }}{\lambda_{\mathrm{opt}}} v^{2} \\
\omega_{\mathrm{opt}}=\frac{\lambda_{\mathrm{opt}} v}{R} .
\end{array}\right.
$$

\section{Simulation Results}

Numerical simulations, using the [25] have been carried out on the NREL WP 1.5-MW wind turbine whose ratings are summarized in Table I [26]. The proposed strategy has been implemented using the available blocks from the Wind Turbine Blockset.

Fig. 8 is then given to illustrate the chosen $1.5-\mathrm{MW}$ wind turbine steady-state power curves at a rated wind speed of about $14 \mathrm{~m} / \mathrm{s}\left(C_{p \max }=0.412\right.$ [12].

The simulations of wind inflow for region II consist of 200 $\mathrm{s}$ data set of full-field turbulent wind that was generated using the Class A Kaimal turbulence spectra. It has a mean value of $9 \mathrm{~m} / \mathrm{s}$ [27].

\section{A. Comparison to Standard Control in Region II}

The proposed control strategy is compared to the standard one in region II (Fig. 8). The obtained results are illustrated in Fig. 10, which obviously shows that the proposed sliding mode approach combined with an MPPT increases power capture in region II. Indeed, with the standard control, a turbine with high rotor inertia spends much of its region II operational times trying to regain the optimal speed ratio lost due to wing gusts and lulls.

Moreover, it should be mentioned that the dynamic characteristics improvement brought by the proposed control approach

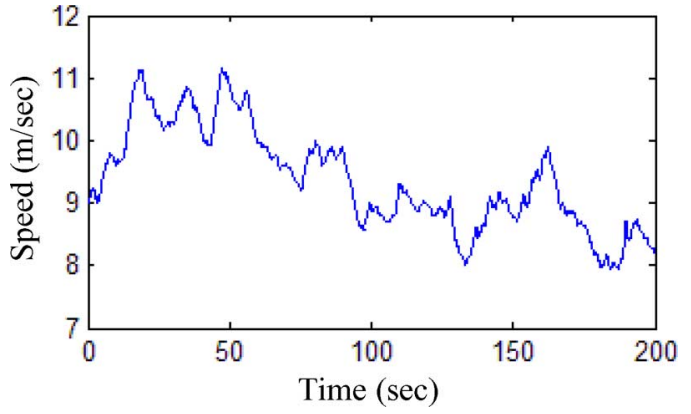

Fig. 9. Wind speed profile for region II.

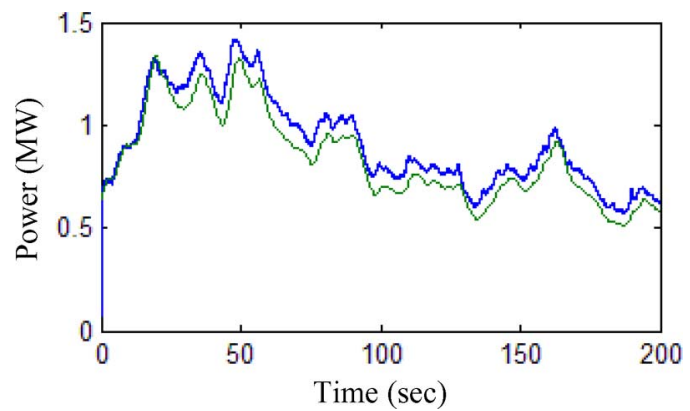

Fig. 10. Generated power: Standard control (lower curve) and sliding mode control (upper curve).

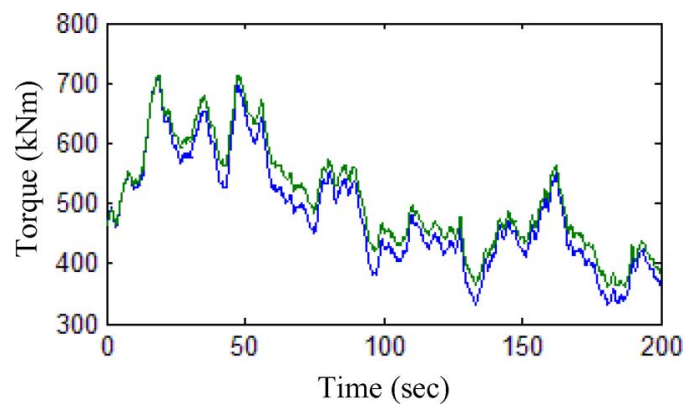

Fig. 11. Generator torque: Standard control (upper curve) and sliding mode control (lower curve).

is as illustrated in Fig. 11. Indeed, slightly lower mechanical stresses are observed.

\section{B. Comparison to Standard Control in Region III}

The distinct region II and region III control objectives lead to many turbines using separate control strategies in region II and region III.

In many turbines, the strategy is as simple as switching from one controller to the other (e.g., constant-pitch, generator torque control in region II to constant torque, variable pitch control in region III). The transition between controllers can cause significant loading on the turbine mechanical and electrical components, with overspeed and overpower transients commonly seen in the industry [28], [29]. In [12], both the pitch and generator torque control are technically "active" at all times, though they are designed so that the pitch reaches its constant saturated 


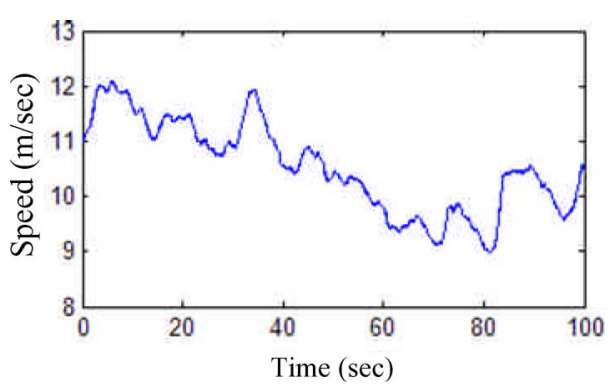

Fig. 12. Wind speed profile for region III.

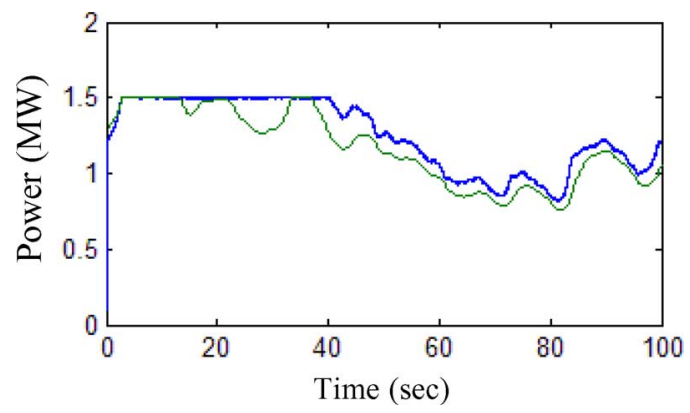

Fig. 13. Generated power: Standard control (lower curve) and sliding mode control (upper curve).

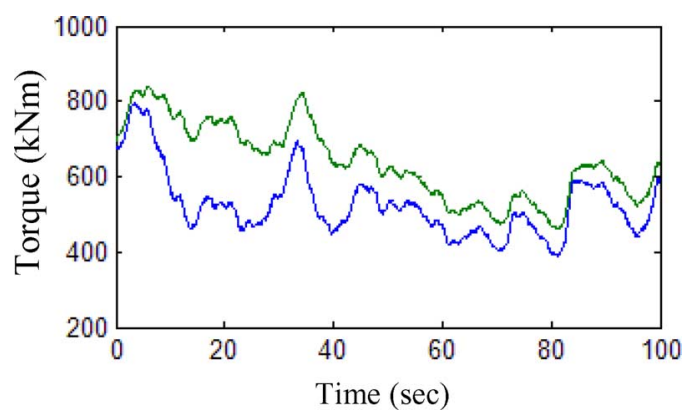

Fig. 14. Generator torque: Standard control (upper curve) and sliding mode control (lower curve).

value in region II, and the generator torque reaches its constant saturated value in region III.

In region III, standard control depowers the wind turbine by changing blade pitch while the turbine speed is kept constant. The proposed dynamic sliding mode control should be active at all times and will avoid mechanical complexity due to pitch control. Nevertheless, in case of high-wind speed, the turbine must be mechanically or aerodynamically braked. Hence, a part of the energy excess is temporarily stored as kinetic energy, which is useful when wind speed decreases.

The obtained results for wind shown in Fig. 12 are illustrated in Figs. 13 and 14. The same tendencies are achieved. These results again point out the superiority of the proposed power control strategy.

\section{VALIDATION RESULTS}

To confirm the encouraging simulation results, the proposed sliding mode power regulation strategy has been tested for validation using the NREL FAST code.

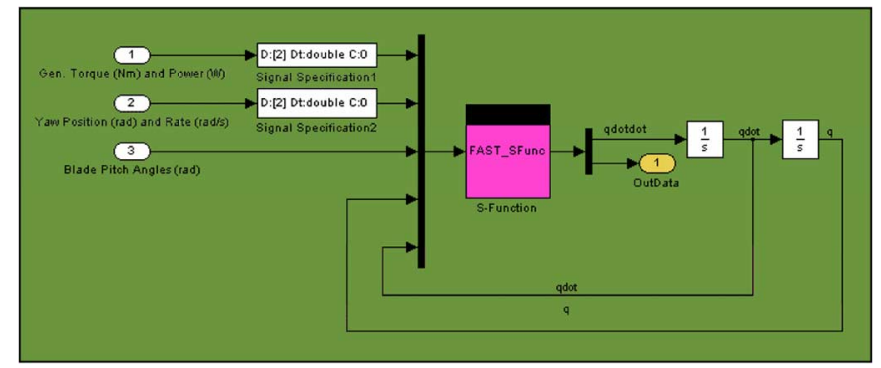

Fig. 15. FAST wind turbine block.

The FAST code is a comprehensive aeroelastic simulator capable of predicting both the extreme and fatigue loads of twoand three-bladed horizontal-axis wind turbines [30]. This simulator has been chosen for validation because in 2005, it was evaluated by Germanischer Lloyd WindEnergie and found suitable for the calculation of onshore wind turbine loads for design and certification [31]. Indeed, it is proven that the structural model of FAST is of higher fidelity than other codes. Therefore, this code has been chosen to validate the proposed sliding mode control approach that was checked by simulation with a simple wind turbine model [7], [8], [12].

\section{A. FAST Briefly and Implementation}

During time-marching analysis, the FAST makes it possible to control the turbine and model-specific conditions in many ways. Five basic methods of control are available: pitching the blades, controlling the generator torque, applying the HSS brake, deploying the tip brakes, and yawing the nacelle. The simpler methods of controlling the turbine require nothing more than setting some of the appropriate input parameters in the turbine control section of the primary input file. Methods of control that are more complicated (that is our case) require writing specific routines, compiling them, and linking them with the rest of the program [32].

An interface has also been developed between the FAST and the Simulink with Matlab enabling users to implement advanced turbine controls in Simulink convenient block diagram form.

The FAST subroutines have been linked with a Matlab standard gateway subroutine in order to use the FAST equations of motion in an S-Function that can be incorporated in a Simulink model. This introduces tremendous flexibility in wind turbine controls implementation during simulation. Generator torque control, nacelle yaw control, and pitch control modules can be designed in the Simulink environment and simulated while making use of the complete nonlinear aeroelastic wind turbine equations of motion available in FAST.

The wind turbine block, as shown in Fig. 15, contains the SFunction block with the FAST motion equations. It also contains blocks that integrate the degree of freedom accelerations to get velocities and displacements. Thus, the equations of motion are formulated in the FAST S-Function but solved using one of the Simulink solvers. The Simulink model should appear as in Fig. 16 next. 


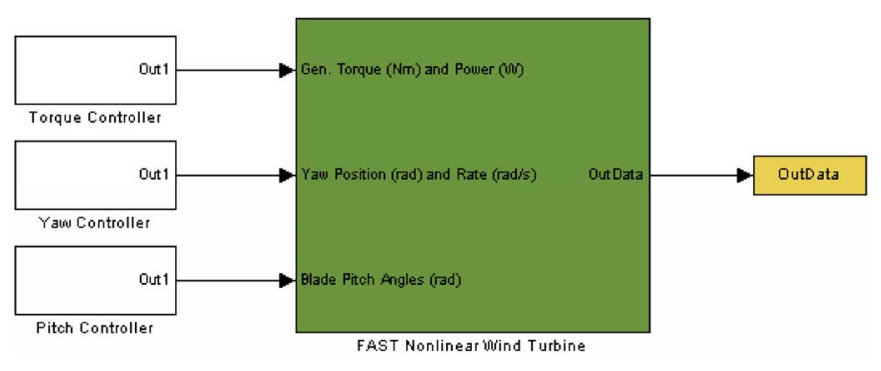

Fig. 16. Simulink model.

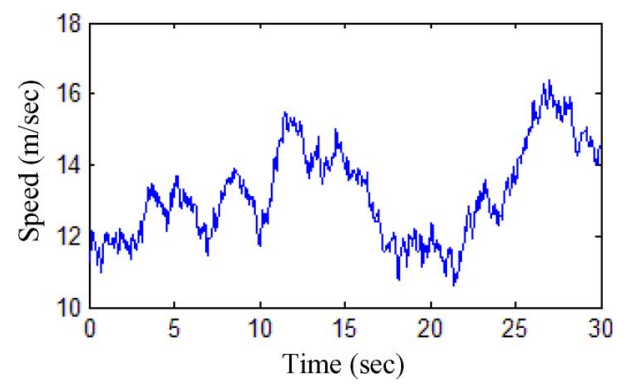

Fig. 17. Wind speed profile.

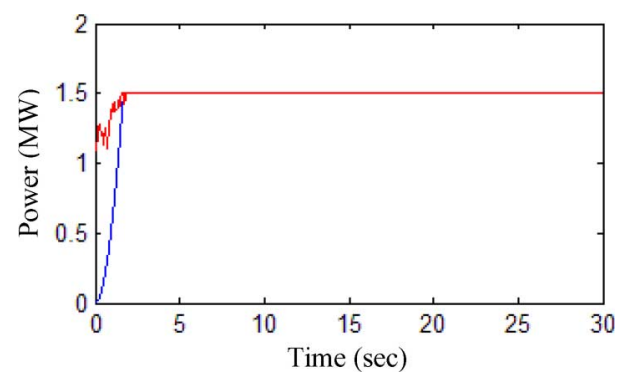

Fig. 18. Generated power (rising) and its MPPT reference.

\section{B. Validation Results}

The sliding mode control strategy combined to an MPPT has been validated on the same simulated WP 1.5-MW wind turbine. The main objective using the FAST is now to test power tracking and regulation performances particularly in region III. The proposed control strategy is also compared to the standard one.

Validation tests were performed using the FAST wind data shown in Fig. 17. The obtained performances are shown to be as expected: very good power tracking and regulation with fast convergence (Fig. 18). Validations also confirm the superiority of the sliding mode control strategy over the standard one (Fig. 19). Moreover, the dynamic characteristics improvement brought are also confirmed (Fig. 20). As expected the torque generator remains smooth. These result in the reduction of the drive train mechanical stresses and output power fluctuations (Fig. 19).

\section{CONCLUSION}

This paper dealt with the problem of controlling power generation in variable-speed wind turbines. For that purpose, a sliding mode control strategy was proposed to ensure stability in both

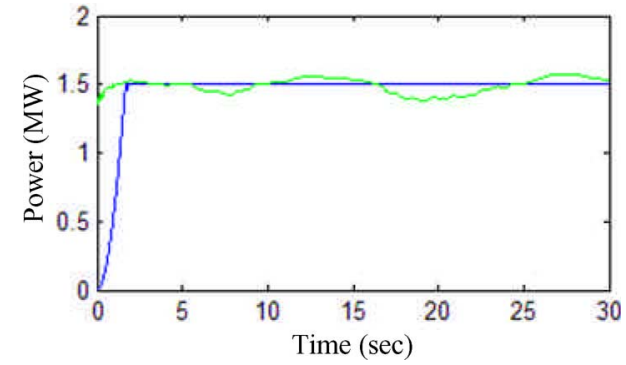

Fig. 19. Generated power: Standard control (oscillating curve) and sliding mode control (continuous curve).

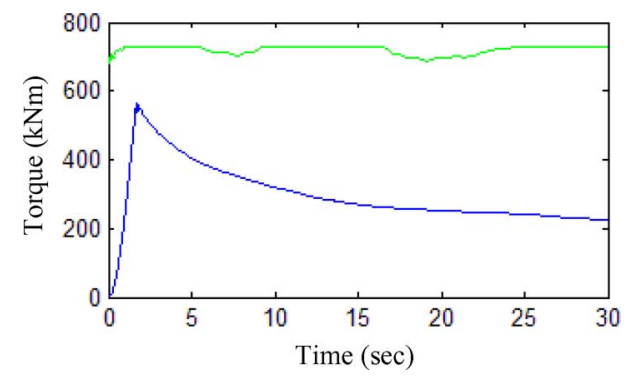

Fig. 20. Generator torque: Standard control (upper curve) and sliding mode control (lower curve).

operation regions and to impose the ideal feedback control solution despite model uncertainties. The proposed sliding mode control strategy presents attractive features such as robustness to parametric uncertainties of the turbine and the generator as well as to electric grid disturbances.

The proposed sliding mode control approach has been simulated on a 1.5-MW three-blade wind turbine to evaluate its consistency and performance. Then, it has been validated using the NREL wind turbine simulator FAST.

Both simulation and validation results show that the proposed control strategy is effective in terms of power capture and regulation. Dynamic characteristics are also improved; resulting in the reduction of the drive train mechanical stresses and output power fluctuations

The main advantages of the proposed sliding mode power control strategy, according to the available literature [7], [8], [12], [15], [17] are: simplicity and robustness against parameter uncertainties and modeling inaccuracies; providing a suitable compromise between conversion efficiency and drive train mechanical stresses; and being active in all operating regions thus avoiding mechanical complexity due to pitch control in region III.

The states of the system (variable-speed wind turbine) were supposed available. The next step of this work is to extend the control to the case of unmeasured states by combining the sliding mode controller to a nonlinear observer.

\section{REFERENCES}

[1] GWEC. (2006, Sep.) "Global wind energy outlook," in Global Wind Energy Council Report [Online]. Available: http://www.gwec.net/

[2] L. Soder, L. Hofmann, A. Orths, H. Holttinen, Y. Wan, and A. Tuohy, "Experience from wind integration in some high penetration areas," IEEE Trans. Energy Convers., vol. 22, no. 1, pp. 4-12, Mar. 2007. 
[3] G. M. J. Herbert, S. Iniyan, E. Sreevalsan, and S. Rajapandian, "A review of wind energy technologies," Renew. Sustainable Energy Rev., vol. 11, no. 6, pp. 1117-1145, Aug. 2007.

[4] Y. Amirat, M. E. H. Benbouzid, B. Bensaker, and R. Wamkeue, "The state of the art of generators for wind energy conversion systems," presented at the ICEM'2006, Chania, Crete Island, Greece.

[5] N. R. Ullah and T. Thiringer, "Variable speed wind turbines for power system stability enhancement," IEEE Trans. Energy Convers., vol. 22, no. 1, pp. 52-60, Mar. 2007.

[6] Y. D. Song, B. Dhinakaran, and X. Y. Bao, "Variable speed control of wind turbines using nonlinear and adaptive algorithms," J. Wind Eng. Ind. Aerodyn., vol. 85, pp. 293-308, 2000.

[7] B. Boukhezzar and H. Siguerdidjane, "Nonlinear control of variable speed wind turbines for power regulation," in Proc. IEEE CCA'2005, Toronto, ON, Canada, vol. 3, pp. 114-119.

[8] B. Boukhezzar, L. Lupu, H. Siguerdidjane, and M. Hand, "Multivariable control strategy for variable speed variable pitch wind turbine," Renew. Energy, vol. 32, no. 8, pp. 1273-1287, Jul. 2007.

[9] E. Bossanyi, Wind Energy Handbook. New York: Wiley, 2000.

[10] E. B. Muhando, T. Senjyu, N. Urasaki, A. Yona, H. kinjo, and T. Funabashi, "Gain scheduling control of variable speed WTG under widely varying turbulence loading," Renew. Energy, vol. 32, no. 14, pp. 2407-2423, Nov. 2007.

[11] T. Senjyu, R. Sakamoto, N. Urasaki, T. Funabashi, H. Fujita, and H. Sekine, "Output power leveling of wind turbine generator for all operating regions by pitch angle control," IEEE Trans. Energy Convers., vol. 21, no. 2, pp. 467-475, Jun. 2006

[12] K. E. Johnson, "Adaptive torque control of variable speed wind turbines," Natl. Renew. Energy Lab., Golden, CO, NREL/TP-500-36265, Aug. 2004.

[13] M. M. Hand, K. E. Johnson, L. J. Fingersh, and A. D. Wright, "Advanced control design and field testing for wind turbines at the National Renewable Energy Laboratory," Natl. Renew. Energy Lab. Golden, CO, NREL/CP500-36118, May 2004.

[14] K. D. Young, V. I. Utkin, and U. Ozguner, "A control engineer's guide to sliding mode control," IEEE Trans. Control Syst. Technol., vol. 7, no. 3, pp. 328-342, May 1999.

[15] H. de Battista and R. J. Mantz, "Dynamical variable structure controller for power regulation of wind energy conversion systems," IEEE Trans. Energy Convers., vol. 19, no. 4, pp. 756-763, Dec. 2004.

[16] F. Valenciaga, P. F. Puleston, and P. E. Bettaiotto, "Power control of a solar/wind generation system without wind measurement: A passivity/sliding mode approach," IEEE Trans. Energy Convers., vol. 18, no. 4, pp. 501-507, Dec. 2003.

[17] H. de Battista, R. J. Mantz, and C. F. Christiansen, "Dynamical sliding mode power control of wind driven induction generators," IEEE Trans. Energy Convers., vol. 15, no. 4, pp. 451-457, Dec. 2000.

[18] F. Valenciaga, P. F. Puleston, and P. E. Battaiotto, "Passivity/sliding mode control of a stand-alone hybrid generation system," in Proc. IEEE Control Theory Appl., Nov. 2000, vol. 147, no. 6, pp. 680-686.

[19] H. de Battista, P. F. Puleston, R. J. Mantz, and C. F. Christiansen, "Sliding mode control of wind energy systems with DOIG-power efficiency and torsional dynamics optimization," IEEE Trans. Power Syst., vol. 15, no. 2, pp. 728-734, May 2000.

[20] H. Camblong, I. Martinez de Alegria, M. Rodriguez, and G. Abad, "Experimental evaluation of wind turbines maximum power point tracking controllers," Energy Convers. Manage., vol. 47, no. 18-19, pp. 28462858, Nov. 2006.

[21] E. Koutroulis and K. Kalaitzakis, "Design of a maximum power tracking system for wind-energy-conversion applications," IEEE Trans. Ind. Electron., vol. 53, no. 2, pp. 486-494, Apr. 2006.

[22] R. Datta and V. T. Ranganathan, "A method of tracking the peak power points for a variable speed wind energy conversion system," IEEE Trans. Energy Convers., vol. 18, no. 1, pp. 163-168, Mar. 2003.

[23] H. K. Khalil, Nonlinear Systems. New York: MacMillan, 1992.

[24] G. Ramtharan, J. B. Ekanayake, and N. Jenkins, "Frequency support from doubly fed induction generator wind turbines," IET Renew. Power Gener., vol. 1, no. 1, pp. 3-9, Mar. 2007.

[25] F. Iov, F. Blaabjerg, C. Zhe, A. D. Hansen, and P. Sorensen, "A new simulation platform to model, optimize and design wind turbines," in Proc. IEEE IECON'2002, Seville, Spain, vol. 1, pp. 561-566.

[26] M. L. Buhl and A. Manjock, "A comparison of wind turbine aeroelastic codes used for certification," Natl. Renew. Energy Lab., Golden, CO, NREL/CP-500-39113, Jan. 2006.

[27] J. Mann, "Wind field simulation," Probab. Eng. Mech., vol. 13, no. 4, pp. 269-282, 1998.
[28] A. Eggers, P. Moriarty, K. Chaney, R. Digumarthi, and W. E. Holley, "Influence of transition modes and gravity loads on rotor fatigue and power control," in Proc. ASME Wind Energy Symp., Reno, NV, Jan. 2002, pp. 237-245.

[29] D. Leith and W. E. Leithead, "Implementation of wind turbine controllers," Int. J. Control, vol. 66, no. 3, pp. 349-380, Feb. 1997.

[30] National Renewable Energy Laboratory, Golden, CO. (2007, Feb) [Online]. Available: http://wind.nrel.gov/designcodes/simulators/fast/

[31] A. Manjock, "Design codes FAST and ADAMS ${ }^{\circledR}$ for load calculations of onshore wind turbines," Germanischer Loyd WindEnergie $\mathrm{GmbH}$, Hamburg, Germany, Rep. 72042, May 26, 2005.

[32] J. M. Jonkman and M. L. Buhl, "FAST user's guide," Natl. Renew. Energy Lab., Golden, CO, NREL/EL-500-38230, Aug. 2005.

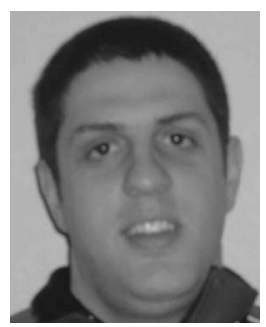

Brice Beltran was born in Arles, France, in 1981. He received the Engineer degree in electrical engineering from the Ecole Nationale Supérieure d'Ingénieurs des Etudes et Techniques d'Armement (ENSIETA), Brest, France, in 2006.

In 2006, he joined the Délégation Générale pour l'Armenent (DGA) as an Engineer and Technical Expert in information systems. He is currently working toward the Ph.D. degree at the Laboratoire de Mécanique et des Systèmes (LBMS), University of Western Brittany, Brest.

His current research interests include wind energy conversion systems' advanced control, and fault-tolerant control.

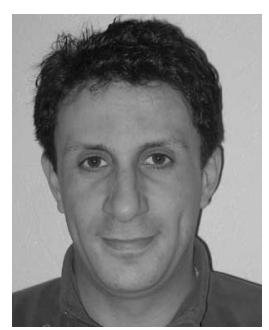

Tarek Ahmed-Ali was born in Algiers, Algeria, in 1972. He received the B.Sc. degree in electrical engineering from the Ecole Nationale Polytechnique of Algiers, Algiers, in 1994, the M.Sc. degree in electrical and computer engineering from the University of Paris VI, Paris, France, in 1995, and the Ph.D. degree in electrical and computer engineering from the University of Paris Sud, Paris, in 1998.

In 1998, he joined the University of Paris XIII, Paris, as a Teaching and Research Assistant. In 1998, he moved then to the Ecole Centrale de Lille, Lille, France, where he was a Teaching and Research Assistant. In 2000, he was appointed Research and Development Engineer at the French Railway Corporation (SNCF). In 2002, he was appointed as a Lecturer in Control Engineering at the Ecole Nationale des Ingénieurs des Etudes et Techniques de l'Armement of Brest, Brest, France. His current research interests include sliding mode control, nonlinear observers, and fault-tolerant control and diagnosis in the field of ac drives.

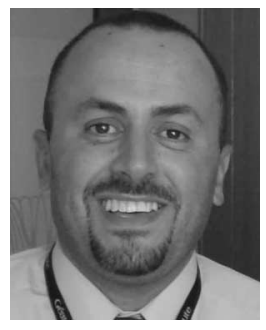

Mohamed El Hachemi Benbouzid (S'93-M'95SM'98) was born in Batna, Algeria, in 1968. He received the B.Sc. degree in electrical engineering from the University of Batna, Batna, in 1990, the M.Sc. and Ph.D. degrees in electrical and computer engineering from the National Polytechnic Institute of Grenoble, Grenoble, France, in 1991 and 1994, respectively, and the Habilitation à Diriger des Recherches degree from the University of Picardie "Jules Verne," Amiens, France, in 2000.

In 2000, he joined the Professional Institute of Amiens, University of Picardie "Jules Verne," where he was an Associate Professor of Electrical and Computer Engineering. In September 2004, he joined the Laboratoire d'Ingénierie Mécanique et Electrique (LIME), University Institute of Technology (IUT) of Brest, University of Western Brittany, Brest, France, as a Professor of Electrical Engineering. His current research interests include analysis, design, and control of electric machines, variable-speed drives for traction and propulsion applications, and fault diagnosis of electric machines.

Prof. Benbouzid is a Senior Member of the IEEE Power Engineering, Industrial Electronics, Industry Applications, Power Electronics, and Vehicular Technology Societies. He is an Associate Editor of the IEEE TRANSACTIONS ON ENERGY CONVERSION, the IEEE TRANSACTIONS ON INDUSTRIAL ELECTRONICS, the IEEE TRANSACTIONS ON VEHICULAR TECHNOLOGY, and the IEEE/ASME TRANSACTIONS ON MECHATRONICS. 